\title{
Avaliação de carotenoides e atividade antioxidante da polpa madura do abacate
}

\section{(persea americana mill)}

\author{
Evaluation of carotenoids and antioxidant activity of mature avocado pulp (persea americana mill) \\ Evaluación de carotenoides y actividad antioxidante de pulpa madura de aguacate (persea
} americana mill)

Recebido: 23/06/2021 | Revisado: 01/07/2021 | Aceito: 05/07/2021 | Publicado: 15/07/2021

Francisca das Chagas Gonçalves do Nascimento
ORCID: https://orcid.org/0000-0003-4504-5870
Instituto Federal de Educação, Ciência e Tecnologia do Piauí, Brasil
E-mail: franpibiologa@ gmail.com
Mariana de Morais Sousa
ORCID: https://orcid.org/0000-0003-4625-8026
E-mail mariana@ @ifpi.edu.br
Instituto Federal de Educação, Ciência e Tecnologia do Piaú, Brasil
Victória Maura Silva Bermúdez
ORCID: https://orcid.org/0000-0002-8105-8735
Universidade Federal do Ceará, Brasil
E-mail: vmsbermudez@ gmail.com
Edilene Ferreira da Silva
ORCID: https://orcid.org/0000-0001-7073-7962
Universidade Federal de Santa Catarina, Brasil
E-mail: silvaedilene16@ @hotmail.com
Vera Lúcia Viana do Nascimento
ORCID: https://orcid.org/0000-0003-0071-3863
Instituto Federal de Educação, Ciência e Tecnologia do Piauí, Brasil
E-mail: veravnascimento@ gmail.com

\section{Resumo}

O abacate é um fruto nutritivo da espécie Persea americana Mill, este cultivar híbrido pertence à família botânica Lauraceae e tem sua origem no continente Americano, amplamente produzido no território brasileiro. Embora este fruto tenha um elevado valor nutritivo, pouco se sabe a respeito da sua natureza fitoquímica e propriedades antioxidantes. O objetivo desta pesquisa foi avaliar os teores de carotenoides e a atividade antioxidante na polpa madura de abacate (Persea americana Mill).Foi realizada a extração da polpa do fruto por maceração, as amostras foram analisadas conforme a metodologia descrita na literatura para carotenoides totais, e a atividade antioxidante pelos métodos - ABTS, DPPH E pelo FRAP. a quantificação dos parâmetros fitoquímicos foi realizada por média e desvio padrão. e a avaliação estatística foi determinada por meio da análise de variância e comparação pelo teste de Tukey com nível de significância $\mathrm{p}<0,05$. os resultados apontam que a polpa do abacate é rica em carotenoides, principalmente $\alpha$-caroteno, cantaxantina, $\beta$-criptoxantina, zeaxantina, $\beta$-caroteno $\mathrm{E} \beta$ - zeacaroteno, ao passo que o fitoflueno apareceu em pequena quantidade $(4,81 \mu \mathrm{g}$ de $\beta$-caroteno) nesta parte do fruto. Os compostos bioativos determinados por DPPH apresentaram resultados que variaram de 41,10 a 98,32 $\mu$ molTrolox. g $^{-1}$, e ABTS, que apresentaram resultados que variaram de $141,54 \mu$ molTrolox. $\mathrm{g}^{-1}$ a 402,14 $\mu$ molTrolox. $\mathrm{g}^{-1}$. Assim, o elevado teor de carotenoides constatado, é fonte de antioxidantes que estabilizam os radicais livres, importantes no combate ao estresse oxidativo.

Palavras-chave: Antioxidantes; Carotenoides; Radical livre; Fitoquímicos; Fruto.

\begin{abstract}
Avocado is a nutritious fruit of the species Persea americana Mill, this hybrid cultivar belongs to the Lauraceae botanical family and has its origin in the American continent, widely produced in the Brazilian territory. Although this fruit has a high nutritional value, little is known about its phytochemical nature and antioxidant properties. The objective of this research was to evaluate the levels of carotenoids and antioxidant activity in the ripe pulp of avocado (Persea americana Mill). The pulp of the fruit was extracted by maceration, the samples were analyzed according to the methodology described in the literature for total carotenoids, and antioxidant activity by the methods - ABTS, DPPH and FRAP. The quantification of phytochemical parameters was performed by means and standard deviations. And the statistical evaluation was determined through analysis of variance and comparison by the Tukey test with a significance level of $\mathrm{p}<0.05$. The results indicate that the avocado pulp is rich in carotenoids, mainly $\alpha$-carotene, canthaxanthin, $\beta$-cryptoxanthin, zeaxanthin, $\beta$-carotene and $\beta$-zeacarotene, whereas phytofluene appeared in a small
\end{abstract}


amount (4.81 $\mu \mathrm{g}$ of $\beta$-carotene) in this part of the fruit. The bioactive compounds determined by DPPH showed results ranging from 41.10 to $98.32 \mu$ molTrolox.g-1, and ABTS, which showed results ranging from 141 , 54 $\mu$ molTrolox.g-1 to $402.14 \mu$ molTrolox.g- ${ }^{1}$. Thus, the high content of carotenoids found, is a source of antioxidants that stabilize free radicals, important in combating oxidative stress.

Keywords: Antioxidants; Carotenoids; Free radical; Fruit; Phytochemicals.

\section{Resumen}

El aguacate es un fruto nutritivo de la especie Persea americana Mill, este cultivar híbrido pertenece a la familia botánica Lauraceae y tiene su origen en el continente americano, ampliamente producido en el territorio brasileño. Aunque esta fruta tiene un alto valor nutricional, se sabe poco sobre su naturaleza fitoquímica y sus propiedades antioxidantes. El objetivo de esta investigación fue evaluar los niveles de carotenoides y la actividad antioxidante en la pulpa madura de aguacate (Persea americana Mill). La pulpa del fruto se extrajo por maceración, las muestras se analizaron según la metodología descrita en la literatura para carotenoides totales, y actividad antioxidante por los métodos - ABTS, DPPH y FRAP. La cuantificación de los parámetros fitoquímicos se realizó mediante medias y desviaciones estándar. Y la evaluación estadística se determinó mediante análisis de varianza y comparación mediante la prueba de Tukey con un nivel de significancia de $\mathrm{p}<0.05$. Los resultados indican que la pulpa de aguacate es rica en carotenoides, principalmente $\alpha$-caroteno, cantaxantina, $\beta$-criptoxantina, zeaxantina, $\beta$-caroteno y $\beta$-zeacaroteno, mientras que fitoflueno apareció en pequeña cantidad $(4,81 \mu \mathrm{g}$ de $\beta$-caroteno) en esta parte de la fruta. Los compuestos bioactivos determinados por DPPH mostraron resultados que variaron de 41,10 a 98,32 $\mu$ molTrolox.g-1, y ABTS, que mostraron resultados que variaron de 141, $54 \mu$ molTrolox.g-1 a 402,14 $\mu$ molTrolox.g- ${ }^{1}$. Así, el alto contenido de carotenoides encontrado, es una fuente de antioxidantes que estabilizan los radicales libres, importante en la lucha contra el estrés oxidativo.

Palabras clave: Antioxidantes; Carotenoides; Fitoquímicos; Fruta; Radicales libres.

\section{Introdução}

O abacate pertencente à espécie Persea americana Mill inserido na família botânica Lauraceae é um importante fruto tropical rico em ácidos graxos insaturados, fibras, vitaminas B e E, e outros nutrientes (Dabas et al., 2019), com origem no continente americano, sendo este cultivar híbrido amplamente produzido no território brasileiro (Oliveira \& Menezes, 2017). É um fruto climatérico que apresenta uma alta taxa de respiração e produção de etileno pós-colheita e consequentemente, é um dos alimentos mais perecíveis e com prazo de validade muito limitado (Islam; Wahid \& Dinh, 2018).

No Brasil a polpa é a principal parte do abacate utilizada para consumo in natura, na forma de sobremesa, sorvetes, saladas, com leite, açúcar, mel, limão e leite condensado, além de ser utilizada para extração de óleo que pode ser empregado pela indústria cosmética e farmacêutica. Em diversos países, é consumido na forma de espaguetes, saladas, guacamole, pizza, tortas, além de sopas, maionese, molhos e pastas. Na área industrial, o abacate é matéria-prima para a extração de azeite e etanol, visando à produção de biocombustível de primeira ou segunda geração e fabricação de tintas (Daiuto et al., 2014; Oliveira \& Santos, 2016; Kowalski et al., 2017).

Este fruto tem ação antioxidante pelo fato de ter na sua composição carotenoides, tocoferóis e fitoesteróis, sendo que os carotenoides apresentam um fragmento de base estrutural e uma cadeia poli-insaturada conjugada, onde esse fragmento é o principal responsável pela capacidade desses compostos para inibir os radicais livres evitando o estresse oxidativo (Dreher \& Davenport, 2013; Santos-Sanchez et al., 2019). O termo radical livre refere-se às moléculas com átomos altamente reativos, que contêm número ímpar de elétrons em sua última camada eletrônica que em excesso podem causar danos às células e aos tecidos dos seres vivos (Silva et al., 2016).

O abacate destaca-se por ser um dos alimentos mais completos, pois contém uma variedade de nutrientes essenciais e fitoquímicos importantes. Além disso, contém diversos sais minerais, sendo consumido por vários países nas principais refeições do dia (Dreher \& Davenport, 2013). Ressalta-se ainda, que a polpa do abacate se caracteriza por apresentar, em média, 1,63\% de proteína, 1,28\% de cinzas, 66, 27\% de umidade, 25, 47\% de lipídios e 5,35\% de carboidratos. O grau de maturação do fruto exerce influência na composição centesimal do mesmo, ou seja, na proporção que cada componente se apresenta no alimento (Ferrari, 2015). 
A polpa carnuda do abacate proporciona a extração de um óleo de alta qualidade, apresentando diversos compostos bioativos. Entre estes compostos importantes temos os carotenoides que são compostos químicos que têm a capacidade de reagir contra os radicais livres diminuindo os seus efeitos nocivos à saúde (Oliveira \& Menezes, 2017; Oliveira et al., 2017).

O óleo de abacate caracteriza-se por apresentar, em média, teores elevados de ácidos graxos monoinsaturados (60\%), teor intermediário de ácidos graxos saturados (24\%) e baixo teor de ácidos graxos poli-insaturados (16\%). O ácido graxo oléico (ômega-9) é o de maior concentração (aproximadamente 55\%). Os principais esteróis, tocoferóis e carotenoides encontrados foram $\beta$-sitosterol, $\alpha$-tocoferol e luteína, respectivamente (Nogueira-de-Almeida et al., 2018).

Variações na cadeia poli-insaturada de um carotenoide para outro, juntamente com a presença de grupos de hidroxila, modificam substancialmente a reatividade dos carotenóides. Das diversas espécies de carotenóides, os três mais comumente encontrados no abacate são $\beta$-criptoxantina, luteína e a zeaxantina. Como os carotenoides são moléculas lipossolúveis, o abacate favorece a absorção destes por ter um alto teor lipídico (Souza, 2014; Nassau, 2013).

$\mathrm{O}$ abacate é um fruto com alta qualidade nutricional, porém pouco se sabe a respeito da sua natureza fitoquímica e propriedades antioxidantes (Daiuto et al., 2014), pois estudos que abordam sobre este tema são ainda incipientes. Por isso, se faz necessário realizar investigações com o intuito de elucidar se a polpa madura possui uma quantidade considerável de bioativos que podem ser usados com segurança pela população na manutenção e prevenção da saúde.

Diante do exposto, o presente trabalho teve como objetivo avaliar os teores de carotenóides e a atividade antioxidante na polpa madura de abacate (Persea americana Mill). Para tanto, foram preparadas amostras de polpa fresca do abacate por maceração, foram quantificados os carotenoides totais presentes na polpa madura do abacate. Além disso, foi analisada a atividade antioxidante da polpa madura do mesmo por meio dos métodos: ABTS, DPPH e FRAP. A importância desse estudo sobre o fruto foi pelas propriedades antioxidantes dos carotenoides que conferem a este alimento a alegação funcional.

\section{Metodologia}

A pesquisa foi realizada de forma experimental quantitativa com a utilização de médias, desvio padrão e análises estatísticas (Pereira et al., 2018). As análises foram realizadas no laboratório de Tecnologia de produtos de origem vegetal (TPOV) e Bromatologia no Instituto Federal do Piauí (IFPI), Campus Teresina Central em parceria com o Laboratório de Alimentos para análise de antioxidantes e atividade antioxidante - Campus Teresina Zona Sul.

A matéria-prima, os frutos do abacateiro variedade 'Hass', foram adquiridos na feira livre em diferentes boxes do mercado local, levando em consideração seu estado de maturação, completamente maduros. No laboratório, primeiramente, foi realizada uma lavagem para retirada de possíveis sujidades, e em seguida higienizados com água e hipoclorito de sódio a 50 ppm, por 15 minutos, seguida da retirada da polpa.

O planejamento experimental foi do tipo casualizado, foram utilizados 06 abacates, com peso total de $1 \mathrm{~kg}$. Foram realizados 04 tratamentos, 48 análises, 03 triplicadas, totalizando 48 amostras.

Após a higienização e sanitização do abacate maduro, foi realizada a retirada da polpa, foi retirado o caroço e colocado a polpa fresca em um almofariz de porcelana e com pistilo, foi macerado até a polpa ficar pastosa, em seguida colocado em béquer de $250 \mathrm{~mL}$ para dissolução com solvente e água destilada. As amostras foram imediatamente protegidas da ação da luz com papel alumínio utilizado, em seguida foram armazenadas em freezer para posteriores analises.

Foram realizadas análises de carotenoides totais, segundo o método descrito por Rodriguez-Amaya (2001), sendo que, para a leitura de outros carotenoides, foi alterada a faixa de absorbância de acordo com o protocolo original, análise da atividade antioxidante da polpa de abacate, pelo método de sequestro do radical $\mathrm{ABTS}^{\cdot+}$ pelo método de sequestro do radical ABTS•+, executada de acordo com Re et al. (1999). A capacidade antioxidante foi feita pelo método de sequestro do radical 
DPPH', realizada segundo Kim et al. (2002). A intensidade da cor roxa/ amarela foi medida a $515 \mathrm{~nm}$ usando espectrofotômetro Bioespectro modelo SP-220.

Outro método usado também para a determinação da atividade antioxidante foi pelo FRAP, método de redução do íon Fe3+ - FRAP, descrito por Benzie e Strain (1999), modificações de Arnous et al. (2002), onde a intensidade da cor azul foi medida a $620 \mathrm{~nm}$ usando espectrofotômetro Bioespectro modelo SP-220.

A análise estatística dos dados fitoquímicos foi por meio de média \pm SD (desvio padrão), análise de variância (ANOVA) e comparação pelo Teste de Tukey. A significância estatística foi estabelecida em 5\%. Os programas utilizados para realização dessa etapa foi Microsoft Excel e Minitab 17 Statistical Software (2016).

\section{Resultados e Discussão}

\subsection{Carotenoides Totais}

As quantificações dos carotenoides presentes na polpa de abacate estão descritas na Tabela 1, a seguir:

Tabela 1. Carotenoides da polpa madura do abacate (Persea americana Mill), 'Hass'.

\begin{tabular}{lcc}
\hline \multicolumn{1}{c}{ Carotenoides } & Absorbância & Média \pm Desvio Padrão (n=3) \\
\hline Fitoflueno & 348 & $4,81 \pm 1,24$ \\
$\alpha$-zeacaroteno & 421 & $8,41 \pm 0,58$ \\
Crocetena & 422 & $7,70 \pm 1,71$ \\
$\beta$-zeacaroteno & 428 & $7,88 \pm 1,44$ \\
$\alpha$-caroteno & 444 & $9,14 \pm 1,53$ \\
$\beta$-criptoxantina/ zeaxantina & 449 & $8,67 \pm 1,52$ \\
& & \\
$\beta$ - caroteno & 450 & $8,56 \pm 1,98$ \\
Bixina/ $\delta$-caroteno & 456 & $7,09 \pm 1,55$ \\
Rubixantina & 460 & $7,69 \pm 1,59$ \\
r-caroteno & 462 & $7,08 \pm 1,39$ \\
Cantaxantina & 466 & $8,93 \pm 2,59$ \\
Licopeno & 470 & $7,64 \pm 1,42$ \\
\hline
\end{tabular}

Média $=\mu$ g de $\beta$-caroteno.g ${ }^{-1}$ de amostra. Fonte: Autores.

Fitoflueno, $\alpha$-zeacaroteno, Crocetena $\beta$-zeacaroteno. $\alpha$-caroteno, $\beta$-criptoxantina/ zeaxantina, $\beta$ - caroteno, Bixina/ $\delta$ caroteno, Rubixantina, $\Upsilon$-caroteno, Cantaxantina e o Licopeno. Desses os que são encontrados em maior quantidade em ordem decrescente são: $\alpha$-caroteno, cantaxantina, $\beta$-criptoxantina, zeaxantina, $\beta$ - caroteno e $\alpha$-zeacaroteno.

Segundo os achados de Mesquita, Teixeira \& Servulo (2017) existem duas classes de carotenoides: os carotenos e as xantofilas. Onde os primeiros são caracterizados pela presença de uma cadeia formada por carbono e hidrogênio que pode ser linear ou cíclica em um ou dois pontos, ao passo que a segunda tem origem na oxigenação da cadeia hidrocarbônica dos carotenos (Zakar et al., 2016). Na presente pesquisa foram encontrados três carotenos ( $\alpha$ - caroteno, $\beta$ - caroteno, $\alpha$ zeacaroteno) e três xantofilas (cantaxantina, $\beta$-criptoxantina, zeaxantina).

A seguir na Figura 1 são apresentadas as estruturas químicas dos carotenoides que tiveram uma concentração mais significativa no extrato da polpa de abacate analisada. 
Figura 1. Carotenoides presentes em maior quantidade na polpa de abacate. Carotenos à esquerda e Xantofilas à direita.

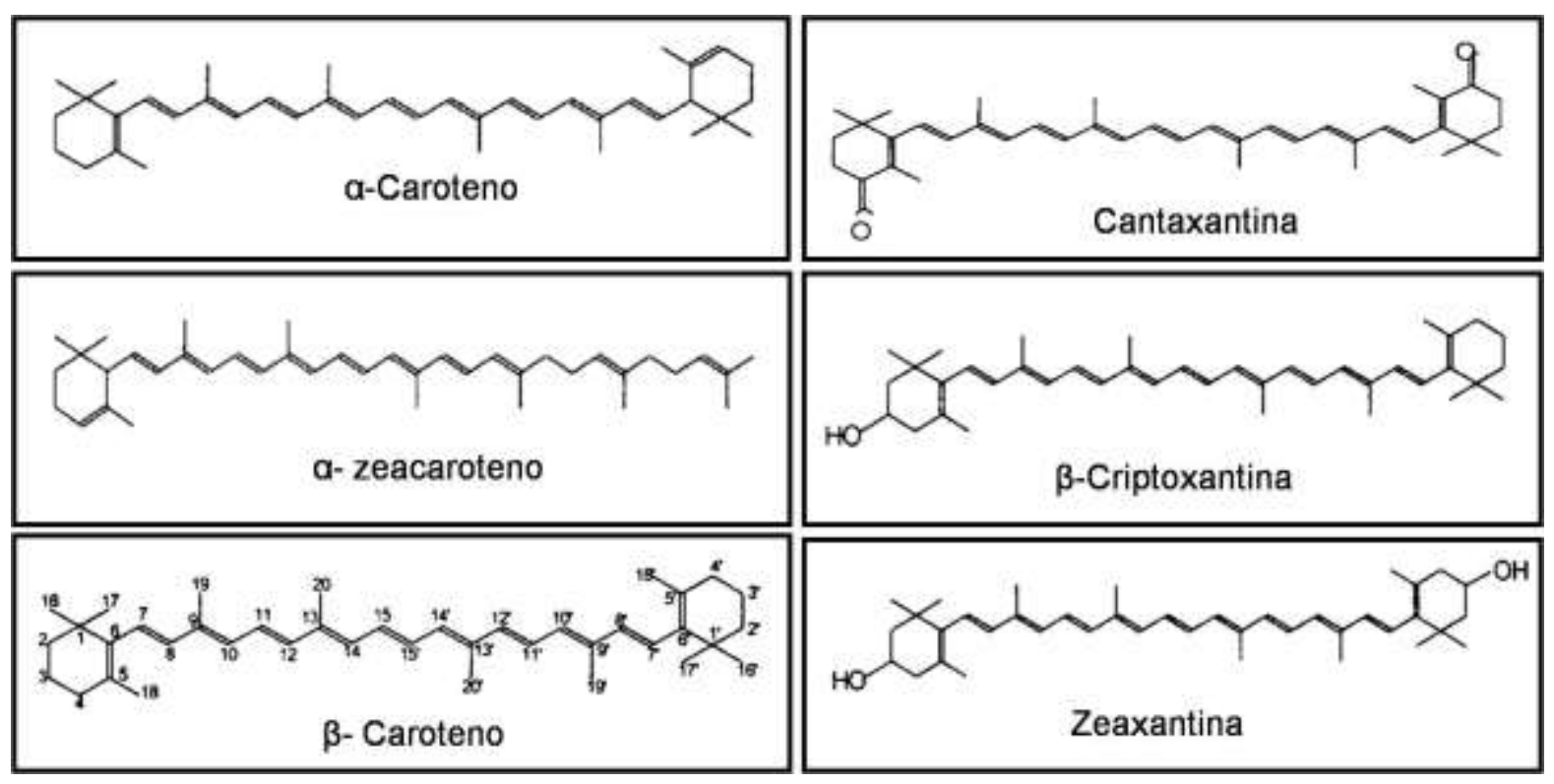

Fonte: Rodriguez-Amaya (2001).

O carotenoide que apresentou uma média maior para o extrato de polpa de abacate foi o $\alpha$-caroteno que teve um valor médio de 9,14 $\mu \mathrm{g}$ de $\beta$-caroteno. $\mathrm{g}^{-1}$ de amostra. Seguido pelo cantaxantina que alcançou uma média de 8,93 $\mu \mathrm{g}$ de $\beta$-caroteno. $\mathrm{g}^{-1}$ de amostra (Tabela 1). O $\alpha$-caroteno presente em frutas e legumes é um carotenoide com atividade pró-vitamina A. Altas concentrações dessa substância no sangue têm sido associda ao menor risco de câncer e baixo índice de mortes por causas diversas (D’adamo et al., 2016). Do mesmo modo foi investigado que a cantaxatina pode atuar reduzindo o crescimento celular induzindo a apoptose, demonstrando que esse carotenoide é capaz de induzir a apoptose em células tumorais. Acrescenta-se ainda que cantaxantina é um agente antioxidante que atua potencializando a resposta imune, a fim de melhorar a comunicação funcional entre as células diretamente ou através da formação de ácido 4-oxo-retinóico, que em uma reação em cadeia é capaz de causar a estimulação do receptor de ácido retinóico (Amaya et al., 2014).

Para o $\beta$-criptoxantina e zeaxantina foi observada uma média de 8,67 $\mu \mathrm{g}$ de $\beta$-caroteno. $\mathrm{g}^{-1}$ de amostra (Tabela 1). $\mathrm{O}$ $\beta$-criptoxantina é um carotenoide pró-vitamina A, ou seja pode ser biologicamente transformado em vitamina A, carotenoide da pró-vitamina A pode ser parcialmente convertido em retinol, no intestino humano pela ação das enzimas oxigenase e redutase e esse composto assim produzido está disponível para absorção. Como a vitamina A e os carotenoides são compostos lipossolúveis, para que sua absorção ocorra da forma adequada é necessário que seja ingerido simultaneamente com lipídios, pois estes compostos acompanham o destino desses macronutrientes no trato gastrointestinal superior (Harrison, 2012; Reboul, 2013). Já a zeaxantina faz parte do grupo de pigmentos que não possui atividade pró-vitamina A, pois a mesma não possui um anel- $\beta$ não substituído, com uma cadeia poliênica de 11 carbonos (Rodrigues-Amaya; Kimura \& Amaya-Farfan, 2008).

Souza (2014) ressalta que a $\beta$-criptoxantina e a zeaxantina juntamente com a luteína são os carotenoides com maior concentração no abacate. Tal afirmação vai ao encontro do que foi observado nesta pesquisa para estes compostos bioativos que tiveram quantidades significativas para os extratos de abacate analisados a exceção da luteína que não fez parte da lista de carotenoides investigados. Cabe salientar que a luteína juntamente com zeaxantina são pigmentos de coloração amarela que se localizam na região macular. Estas substâncias atuam diminuindo e filtrando a quantidade de luz azul visível que chega aos fotorreceptores e também tem ação antioxidante melhorando dessa forma a qualidade da visão (Canovas et al., 2009). 
Ao investigar a ocorrência de $\beta$-caroteno na polpa de abacate foi encontrado um valor de $8,56 \mu \mathrm{g}$ de $\beta$-caroteno. $\mathrm{g}^{-1}$ de amostra (Tabela 1). De acordo com Rodriguez-Amaya (2010) esse pigmento é encontrado, principalmente, em vegetais e frutas de cor amarelo-alaranjada e em vegetais folhosos de cor verde-escura. Nestes, a cor natural do carotenoide é mascarada pela clorofila, presente nos cloroplastos. Pode ser obtido dos alimentos de origem vegetal na forma de pró-vitamina A, sendo essencial para o ser humano.

$\mathrm{Na}$ indústria de alimentos, o $\beta$-caroteno é destinado ao uso como corante alimentar para colorir bebidas, margarina, queijos, recheios de bolo, cremes, iogurtes, nozes processadas, massas e macarrão pré-cozidos entre outros produtos. Ressaltase ainda que esse carotenoide apresenta ação antioxidante devido às suas ligações duplas conjugadas, que são suscetíveis à oxidação sob ação de luz ou oxigênio (Fao, 2017; Lima et al., 2017).

De todos os carotenoides conhecidos com atividade pró-vitamina $\mathrm{A}$, o $\beta$-caroteno se destaca, pelo fato deste composto bioativo apresentar $100 \%$ de atividade em vitamina A, pois a partir dessa molécula são produzidas duas unidades de retinol (Mesquita; Teixeira \& Servulo, 2017). Ele também é um antioxidante clássico dos filtros solares que protege a pele contra os efeitos deletérios induzidos por radiação UVA, onde a sua aplicação tópica neutraliza os radicais livres gerados pela exposição à radiação infravermelha, prevenindo o envelhecimento precoce da pele (Freitas; Lopes \& Gaspar, 2015).

Um outro carotenoide analisado neste ensaio foi $\alpha$-zeacaroteno que teve uma concentração significativa de $8,41 \mu \mathrm{g}$ de $\beta$-caroteno. $\mathrm{g}^{-1}$ de amostra (Tabela 1). Para o extrato da polpa de abacate não há estudos que realizaram investigações a respeito da ocorrência deste carotenoide para o fruto em questão. Ng \& Shoo (2016) obteveram este carotenoide ao realizar um estudo que consistia no aprimoramento de métodos para análises qualitativas de carotenos do óleo de palma.

Ainda na polpa do abacate foram encontrados outros carotenoides, porém, em menores quantidades que os anteriores, mas sua presença neste fruto tem grande relevância para sua natureza fitoquímica. Estes compostos são: $\beta$-zeacaroteno, crocetena, rubixantina, bixina, $\delta$-caroteno, $\Upsilon$-caroteno e licopeno (Tabela 1). A seguir na figura 2 são mostradas as estruturas químicas de outros carotenoides que estão presentes na polpa de abacate.

Figura 2. Estrutura química de outros carotenoides que estão presentes na polpa de abacate.

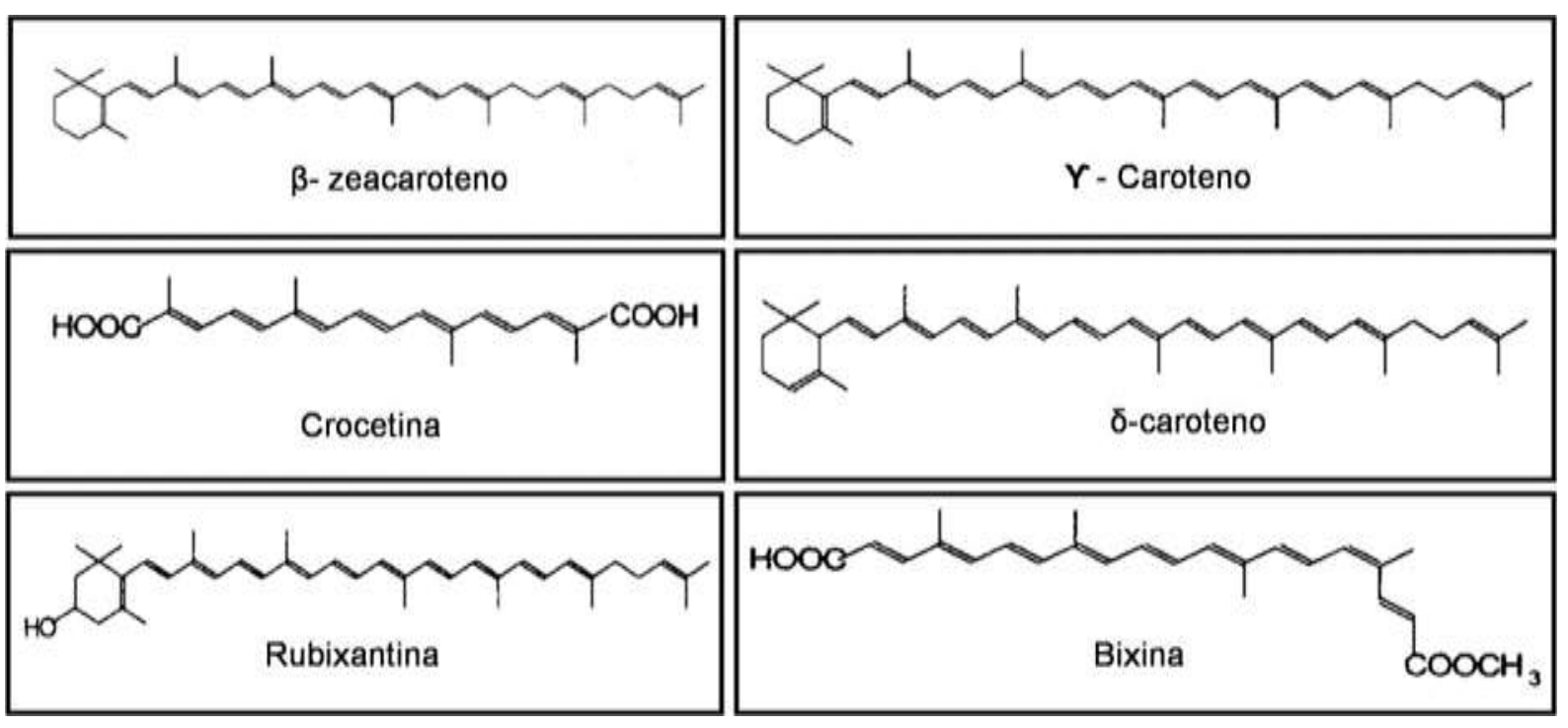

Fonte: Rodriguez-Amaya (2001).

Continuando a análise do extrato da polpa de abacate, para o $\beta$ - zeacaroteno foi encontrado um valor médio de 7,88 $\mu \mathrm{g}$ de $\beta$-caroteno. $\mathrm{g}^{-1}$ de amostra (Tabela 1). O $\beta$-zeacaroteno atua como precursor na biossíntese de carotenoides importantes que 
estão presentes no abacate e em outros grupos de vegetais como o $\beta$-caroteno, $\beta$-criptoxantina, zeaxantina entre outros. Além do mais este carotenoide tem atividade de provitamina A, ou seja, ele pode ser convertido na mucosa intestinal em vitamina A, uma vitamina lipossolúvel que está envolvida no bom funcionamento da visão (Bergamaschi, 2010). Acrescenta-se ainda que este importante carotenoide é classificado como caroteno, pois em sua estrutura química são encontrados somente carbono e hidrogênio. Na literatura não são citados trabalhos que associem este carotenoide com o abacate, sendo ainda pouco conhecido cientificamente.

Para a investigação da crocetina na polpa de abacate foi encontrado uma média de 7,70 $\mu \mathrm{g}$ de $\beta$-caroteno. $\mathrm{g}^{-1}$ de amostra (Tabela 1). É um composto biativo resultado da hidrólise da crocina encontrado no alçafrão (Crocus sativus L.) que apresenta fortes propriedades antioxidantes e que tem ação eliminadora de uma variedade de espécies de radicais livres de oxigênio e citocinas pró-inflamatórias, além da ação anti-tumoral e anticancerígena (Mashmoul et al., 2013). Festuccia et al. (2014) realizaram estudos com camundongos nude machos quanto ao efeito da crocina, crocetina e do extrato do açafrão. Esses autores observaram que a crocetina, apresentou maior efeito anti-tumoral quando comparado com a crocina e o extrato de açafrão. Isso só mostra o quanto essas sustâncias são benéficas para os seres vivos.

A concentração de rubixantina foi dada pela média de 7,69 $\mu \mathrm{g}$ de $\beta$-caroteno. $\mathrm{g}^{-1}$ de amostra (Tabela 1). Este carotenoide tem como precursor o $\Upsilon$-caroteno, sendo também um corante orgânico natural com ampla aplicação na indústria alimentícia. A literatura não cita a rubixantina como um dos carotenoides com quantidade significativa para este fruto, mas nesta pesquisa foi observado que este composto está presente no extrato da polpa de abacate.

Bixina e $\delta$-caroteno tiveram uma concentração de 7,09 $\mu \mathrm{g}$ de $\beta$-caroteno. $\mathrm{g}^{-1}$ de amostra (Tabela 1). A bixina é um carotenoide de cor vermelha, majoritário das sementes, perfazendo um mínimo de $80 \%$ dos carotenoides totais. Foi o primeiro carotenoide natural identificado a possuir configuração cis. Sua estrutura, com 25 carbonos e grupos carboxílicos e éster metílico é muito diferente dos carotenoides que são encontrados nos alimentos atuais, é um pigmento de ocorrência somente no urucum (Bixa orellana L.) sendo um dos corantes naturais mais utilizados no mundo, e o Brasil um dos maiores produtores e exportadores das suas sementes.

$\mathrm{Na}$ indústria alimentícia esse pigmento é frequentemente usado para adicionar cor aos laticínios, como manteiga, queijo ou pudim, creme de biscoitos e sorvetes entre outros produtos (Schiozer \& Barata, 2007; Mala et al., 2015). Já o $\delta$ caroteno é o protótipo do $\alpha$ - caroteno na biossíntese desse importante carotenoide com atividade pró-vitamina A e da luteína que não apresenta atividade pró-vitamina $\mathrm{A}$, mas atua no bom funcionamento da visão evitando a degeneração da mácula, pois é um dos pigmentos macular.

$\Upsilon$-caroteno foi observado uma concentração média de 7,08 $\mu \mathrm{g}$ de $\beta$-caroteno. $\mathrm{g}^{-1}$ de amostra (Tabela 1). É um carotenoide que na rota de biossintese desses compostos bioativos é a substância intemediária na formação de alguns carotenoides importantes encontrados nos alimentos como: $\beta$-caroteno, $\beta$-criptoxantina, zeaxantina entre outros (RodriguesAmaya \& Kimura; Amaya-Farfan, 2008). Sendo os compostos bioativos citados anteriormente mais comuns no abacate segundo a literatura, era de se esperar que $\Upsilon$-caroteno fosse observado em grande quantidade, pois, esse se trata do precursor desses valiosos carotenoides para a saúde dos seres humanos.

Em relação ao licopeno foi encontrada uma média de 7,64 $\mu \mathrm{g}$ de $\beta$-caroteno. $\mathrm{g}^{-1}$ de amostra (Tabela 1). Esse composto bioativo é responsável pela coloração vermelha de diversas frutas, sua estrutura química é formada por unidades de isopreno, contendo onze duplas ligações conjugadas, que confere a esse composto alta capacidade antioxidante. Sua ação antioxidativa ocorre principalmente pela capacidade sequestradora de radicais livres, uma vez que suas moléculas são capazes de receber elétrons de espécies reativas (Freda et al., 2018). A seguir na Figura 3 é mostrada a estrutura química do licopeno, um carotenoide pertencente a classe dos carotenos. 
Figura 3. Estrutura química do Licopeno, um carotenoide da classe dos carotenos.

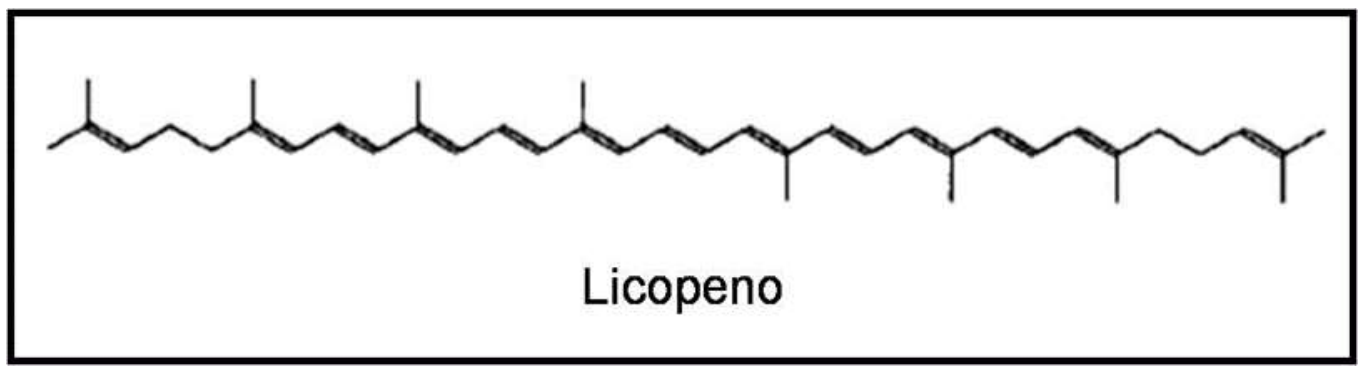

Fonte: Rodriguez-Amaya (2001).

Cabe destacar que o licopeno é um carotenoide não pró-vitamina A, mas é um potente antioxidante que atua na prevenção de doenças cardiovasculares e reage contra espécies reativas de oxigênios e nitrogênios evitando desta forma danos as células e tecidos do organismo (Müller et al., 2015). Acrescenta-se ainda que o licopeno tem papel importante na síntese de carotenoides, pois, ele pode ser considerado o protótipo dos principais carotenoides encontrados nos alimentos: $\alpha$ - caroteno, $\beta$ caroteno, luteína e violaxantina (Rodrigues-Amaya; Kimura \& Amaya-Farfan, 2008). Na indústria alimentícia o licopeno pode ser utilizado como aditivo evitando a degradação oxidativa e descoloração de carnes e também para a produção de alimentos com alegação funcional enriquecidos com esse carotenoide que assegura benefícios à saúde dos seres humanos (Domínguez et al., 2020).

Dos carotenoides analisados para a polpa de abacate o fitoflueno foi o que teve o menor valor registrado para o extrato uma média de 4,81 $\mu \mathrm{g}$ de $\beta$-caroteno. $\mathrm{g}^{-1}$ de amostra (Tabela 1). O fitoflueno juntamente com o fitoeno são carotenoides incolores que podem ser encontrados em frutos que são comuns na dieta humana como: banana, tomates, frutas cítricas, cenouras, abacate entre outros. Além de serem encontrados no plasma humano, no leite, nos tecidos internos e na pele (Havas et al., 2018). Ainda de acordo com esses autores o fitoflueno e o fitoeno podem agir como compostos antixidantes e antiinflamatórios, prevenindo dessa forma o câncer de pele. Observa-se que estes carotenoides apesar da sua ampla importância ainda são pouco estudados. Cabe frisar que o fitoeno não foi detectado em nossas análises para o abacate. A seguir na figura 4 apresenta a estrtura química do fitoflueno, um carotenoide da classe dos carotenos.

Figura 4. Estrutura química do Fitoflueno, um carotenoide da classe dos carotenos.

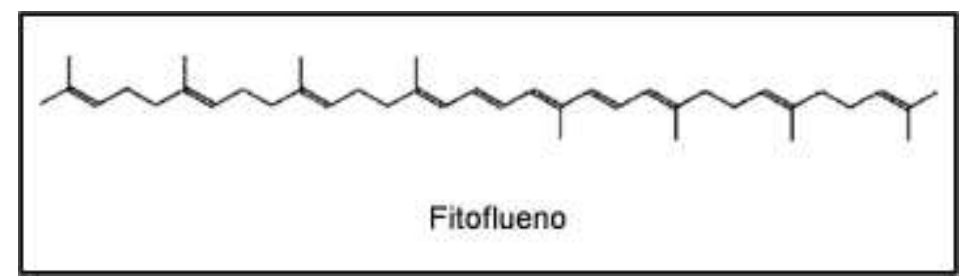

Fonte: Rodriguez-Amaya (2001).

Convém salientar que os principais carotenoides encontrados nos alimentos são o $\beta$-caroteno, $\alpha$-caroteno, $\beta$ criptoxantina, luteína, licopeno e violaxantina. Os cinco primeiros são também os mais encontrados no sangue humano. Juntamente com a zeaxantina, são os carotenoides que trazem benefícios para a saúde humana, sendo importante a sua ingestão através da alimentação (Rodriguez - Amaya 2004). Todos esses compostos bioativos foram quantificados no extrato da polpa de abacate aqui analisada, com exceção da luteína e violaxantina, pois as mesmas não foram investigadas neste estudo. 
Segundo Rodrigues - Amaya, Kimura \& Amaya- Farfan (2008) vários fatores tornam esse tipo de análise difícil no alimento, como por exemplo: a existência de um grande número de carotenoides, a variabilidade qualitativa e quantitativa da composição dos alimentos, a ampla variação nas quantidades dos carotenoides dentro de um mesmo alimento, a distribuição não uniforme dos carotenoides entre amostras e ainda dentro de uma mesma amostra, a natureza variável das matrizes alimentícias, esses e outros fatores causam instabilidade nas análises de carotenoides. Ainda de acordo com esses autores os carotenoides têm a capacidade de sequestro do oxigênio singlete pela presença das ligações duplas conjugadas na sua cadeia carbônica. Além disso, através de estudos foi verificado que o licopeno um carotenoide acíclico é mais eficiente na captura de radicais livres, do que o $\beta$-caroteno um dicíclico, mesmo ambos apresentando 11 duplas ligações conjugadas na cadeia.

\subsection{Atividade Antioxidante}

Os dados referentes à análise do extrato da polpa de abacate para a atividade antioxidante estão reunidos na Tabela 2.

Tabela 2. Atividade Antioxidante da polpa madura do abacate (Persea americana Mill) variedade 'Hass'.

\begin{tabular}{cccc}
\hline Amostras de abacate & $\begin{array}{c}\text { Compostos bioativos } \\
\left(\mu \text { molTrolox. }{ }^{-1}\right)\end{array}$ & Extratos orgânicos & $\begin{array}{c}\text { Polpa de Abacate }(\mathrm{n}=3) \\
\text { média } \pm \text { Desvio Padrão }\end{array}$ \\
\hline A & & & $98,32 \pm 11,51^{\mathrm{a}}$ \\
B & DPPH & & $89,94 \pm 11,44^{\mathrm{a}}$ \\
C & & & $41,10 \pm 6,11^{\mathrm{b}}$ \\
\hline A & \multirow{3}{*}{ ABTS } & Éter de petróleo & $402,14 \pm 64,7^{\mathrm{a}}$ \\
B & & & $189,61 \pm 4,28^{\mathrm{b}}$ \\
C & \multirow{3}{*}{ FRAP } & & $141,54 \pm 1,23^{\mathrm{b}}$ \\
\hline A & & $-99,79 \pm 14,88^{\mathrm{b}}$ \\
B & & $-31,21 \pm 45,3^{\mathrm{b}}$ \\
C & & $56,4 \pm 36,7^{\mathrm{a}}$ \\
\hline
\end{tabular}

Médias que não compartilham mesma letra são significativamente diferentes $(\mathrm{p}<0,05)$ pelo teste de Tukey pelos métodos do DPPH, ABTS e FRAP. Fonte: Autores (2020).

Os compostos bioativos determinados por DPPH apresentaram resultados que variaram de 41,10 a 98,32 $\mu$ molTrolox. $\mathrm{g}^{-1}$, observando diferença estatística $(\mathrm{p}<0,05)$ entre as amostras A e $\mathrm{C}$ (Tabela 2$)$. Tais resultados podem ser devido as condições de extração, a origem da amostra e a metodologia utilizada para determinação de eliminação do radical que podem afetar os resultados obtidos em grande parte dos estudos (Segovia et al., 2018).

Daiuto et al. (2014) ao estudarem a atividade antioxidante do abacate variedade 'Hass' encontram para a polpa uma média de $8,1 \mu \mathrm{mol} \mathrm{TE} / \mathrm{g}$ atividade antioxidante equivalente ao Trolox. Tal valor citado para a polpa difere dos aqui encontrados, pois os valores médios aqui apresentados são superiores aquele observado por estes autores. Vários fatores exercem influência na composição dos metabólitos secundários das diversas partes da planta, incluídos os carotenoides, entre eles podemos citar: a sazonalidade, a temperatura, a altitude, o desenvolvimento, o índice pluviométrico e a idade da planta têm importância considerável na qualidade e quantidade total de metabólitos produzidos (Gobbo-Neto \& Lopes, 2007). Ressalta-se que quanto menor o valor em Trolox maior a absorbância, no caso do ensaio a amostra com valor 41,10 $\mu$ molTrolox. $\mathrm{g}^{-1}$ foi a que apresentou menor atividade antioxidante, pois das três amostras este valor médio foi o menor. Porém superior aquele encontrado por Daiuto et al. (2014) para a polpa de abacate.

Em outro estudo realizado com seis frutas tropicais da Colômbia entre elas o abacate, ficou verificado que esse fruto tem a maior atividade antioxidante com um valor de 165,10 $\mu$ mol de Trolox / $100 \mathrm{~g}$ de amostra (Moreno; Ortiz \& Restrepo, 2014). Segundo Cruz et al. (2015) a provável causa se deve a presença dos carotenoides, flavonoides, $\alpha$-tocoferol e clorofila 
presentes em grande quantidade na polpa de abacate que agem contribuindo desta forma para a estabilização do radical livre DPPH.

Os compostos bioativos determinados por ABTS apresentaram resultados que variaram de 141, $54 \mu$ molTrolox.g ${ }^{-1}$ a 402,14 $\mu$ molTrolox. $\mathrm{g}^{-1}$, observando diferença estatística $(\mathrm{p}<0,05)$ entre as amostras A e C (Tabela 2). Daiuto et al. (2014) também estudaram a atividade antioxidante do abacate variedade 'Hass' pelo método ABTS e constataram que a polpa teve um valor médio de 15,2 $\mu \mathrm{mol} \mathrm{TEAC} / \mathrm{g}^{-1}$ capacidade antioxidante total do composto equivalente ao Trolox. $\mathrm{O}$ valor encontrado para a polpa da variedade 'Hass' citado anteriormente, foi inferior aos encontrados para as amostras aqui analisadas, as quais apresentaram valores altos, infere-se que estes podem ser pelo fato do fruto ainda se encontrar verde, em processo fisiológico de amadurecimento.

Em outro estudo realizado por Amado et al. (2019) onde esses autores analisaram a casca, polpa e semente de quatro variedades de abacate incluindo a "Hass" encontraram um valor médio para a polpa de 2,34 $\mu$ mol TE $\mathrm{g}^{-1}$, equivalente a trolox de amostra de abacate desidratado. Essa média se encontra próxima do valor encontrado por Daiuto et al. (2014), porém diferindo do valor encontrado para este ensaio. Segundo Vinha et al. (2012) a composição nutricional e química das polpas dos frutos pode ser influenciada pela variação geográfica, pelas condições climáticas, a exposição ao sol, a natureza do solo e pelas técnicas agrícolas utilizadas.

Os compostos bioativos determinados por FRAP apresentaram resultados que variaram de $-99,79 \mu$ molTrolox. $\mathrm{g}^{-1}$ a $56,4 \pm 36,7 \mu$ molTrolox. $\mathrm{g}^{-1}$, observando diferença estatística $(\mathrm{p}<0,05)$ entre as amostras A e C (Tabela 2). Os valores das amostras A e B evidencia que a polpa teve maior atividade antioxidante pelo método FRAP.

Moura (2019) ao analisar a atividade antioxidante da polpa e do óleo de abacate encontrou um valor médio de 0,80 $\mu$ mol TE /g equivalente trolox para a polpa utilizando o método FRAP. Este valor encontra-se no intervalo dos valores encontrados para este estudo, corroborando dessa forma com a presente pesquisa. Além disso, a autora ressalta que após investigar o conteúdo de compostos bioativos é possível observar que a polpa de abacate apresenta uma quantidade significativa de compostos fenólicos totais e carotenoides, ambos, desempenham uma função protetora ao tecido cerebral quanto ao ataque de espécies reativas de oxigênio.

Por fim, convém salientar que esse método tem como princípio a redução do ferro, que simula a reação ocorrendo no interior das células vivas. Para se obter um bom resultado da capacidade antioxidante deve-se utilizar os três métodos de captura de elétrons ou hidrogênios e auto-oxidação do ferro, pois um método nem sempre é o suficiente para detectar com precisão a atividade antioxidante de uma amostra.

\section{Conclusão}

Conclui-se que a polpa madura de abacate apresentou alto teor de carotenoides dentre os compostos bioativos, os que apresentaram maior concentração segundo a média estatística foi o $\alpha$-caroteno, a cantaxantina, a $\beta$-criptoxantina, a zeaxantina, o $\beta$ - caroteno e $\alpha$-zeacaroteno.

Salienta-se que a polpa de abacate apresenta excelente atividade antioxidante, essa foi comprovada por meio dos testes ABTS, DPPH e FRAP. Sendo um fruto que pode ser usado para estabilizar os radiais livres que, em excesso, podem levar ao estresse oxidativo.

Para estudos futuros, é importante avaliar outras famílias de carotenoides e antioxidantes que ainda não foram evidenciados no abacate, podendo ser estudado no início do amadurecimento do fruto para posterior comparação. Bem como, a avaliação da amêndoa do abacate também pode ser inserida.

Por fim, ressalta-se que este estudo foi importante para obtermos maior número de compostos bioativos presentes na polpa de abacate, que servirão para auxiliar em mais pesquisas relacionadas ao fruto. 


\section{Agradecimentos}

Agradecimento ao Laboratório de Alimentos do IFPI -Campus Teresina /Zona Sul.

\section{Referências}

Amado, D. A. V., Helmanng. A. B., Detoni, A. M., Carvalho, S. L. C., Aguiar, C. M., Martin, C. A., Tiuman, T. S. \& Cottica, S. M. (2019). Antioxidant and antibacterial activity and preliminary toxicity analysis of four varieties of avocado (Persea americana Mill.). Brazilian Journal Food of Technology, 22, e2018044, 1-11. http://www.scielo.br/pdf/bjft/v22/1981-6723-bjft-22-e2018044.pdf.

Amaya, E., Becquet, P., Carné, S., Peris, S. \& Miralles, P. (2014). Carotenoids in animal nutrition. Fefana, 51p. http://fefana.org/publication/carotenoids-inanimal-nutrition/.

Arnous, A., Makris, D. P. \& Kefalas, P. (2002). Correlation of Pigment and Flavanol Content with Antioxidant Properties in Selected Aged Regional Wines from Greece. Journal of Food Composition and Analysis, 15, 655-665. https://www.sciencedirect.com/science/article/abs/pii/S0889157502910707.

Benzie, I., \& Strain, J. (1999). Ferric reducing/antioxidant power assay: Direct measure of total antioxidant activity of biological fluids and modified version for simultaneous measurement of total antioxidant power and ascorbic acid concentration. Methods in Enzymology, 299, 15-27. doi.org/10.1016/S00766879(99)99005-5.

Bergamaschi, K. B. (2010). Capacidade antioxidante e composição química de resíduos vegetais visando seu aproveitamento. Dissertação de Mestrado, Escola Superior de Agricultura Luiz de Queiroz, Universidade de São Paulo, Piracicaba. 10.11606/D.11.2010.tde-10022011-144122

Canovas, R., Cypel, M., Farah, M. E. \& Belfort JR, R. (2009). Pigmentos maculares. Arquivos Brasileiros de Oftalmologia, 72, 839-44. http://www.scielo.br/pdf/abo/v72n6/21.pdf.

Cruz, E., Dueñas, M., García, L., Salinas, Y., Santos, C. \& García, C. (2015). Anthocyanin and phenolic characterization, chemical composition and antioxidant activity of chagalopi (Ardisia compressa K.) fruit: A tropical source of natural pigments. Food Research International, 70, 151-157. https://www.infona.pl/resource/bwmeta1.element.elsevier-9d595231-5498-3dc2-abbf-033af19c6227.

D’adamo, C. R., Dawson, V. J., Ryan, K. A., Yerges-Armstrong, L. M., Semba, R. D., Steinle, N. I., Mitchell, B. D., Shuldiner, A. R.\& Mcardle, P. F. (2016). The CAPN2/CAPN8 Locus on Chromosome 1q Is Associated with Variation in Serum Alpha-Carotene Concentrations. Journal Nutrigenet Nutrigenomics, v9, 254-264. https://www.karger.com/Article/FullText/452890.

Dabas, D., Elias, R. J., Ziegler, G. R. \& Lambert, J. D. (2019). In Vitro Antioxidant and Cancer Inhibitory Activity of a Colored Avocado Seed Extract. International Journal of Food Science, 2, 1-7. https: //www.hindawi.com/journals/ijfs/2019/6509421/.

Daiuto, E. R., Tremocoldi, M. A., Alencar, S. M., Vieites, R. L. \& Minarelli, P. H. (2014). Composição química e atividade antioxidante da polpa e resíduos de abacate 'Hass'. Revista Brasileira de Fruticultura, 36, 417-424. http://www.scielo.br/pdf/rbf/v36n2/v36n2a18.pdf.

Domínguez, R., Gullón P., Pateiro, M., Munekata, P. E. S., Zhang, W. \& Lorenzo, J. M. (2020). Tomato as Potential Source of Natural Additives for Meat Industry. A Review. Antioxidants, 9, 1-22. https://www.mdpi.com/2076-3921/9/1/73.

Dreher, M. L. \& Davenport, A. J. (2013). Hass avocado composition and potential health effects. Critical Reviews in Food Science and Nutrition, USA, v. 53, 738-750. http://dx.doi.org/1 0.1080/10408398.2011.556759.

Ferrari, R. A. (2015). Caracterização físico-química do óleo de abacate extraído por centrifugação e dos subprodutos do processamento. Brazilian Journal of Food Technology, 18, 79-84. http://www.scielo.br/pdf/bjft/v18n1/1981-6723-bjft-18-1-79.pdf.

Festuccia, C., Mancini, A., Gravina, G. L., Scarsella, L. L., Lorens, S., Gonzalo, L. A., Carla T. C., Di Cesare, E., Jannini, A. E., Andrea Lenzi, A., D’Alessandro, A. M. \& Carmona, M. (2014). Antitumor effects of saffron derived carotenoids in prostate câncer cell models. BioMed Research International, 2014, 1-13. http://downloads.hindawi.com/journals/bmri/2014/135048.pdf.

Food and Agriculture Organization of the United Nations- FAO. Beta-carotene-rich extract from Dunaliella salina. Prepared by Kristie B. Laurvick. (2017). Chemical and Technical Assessment. http://www.fao.org/3/BU603en/bu603en.pdf.

Freda, S.A., Luvielmo, M. M., Rutz, J. K., Zambiazi, R. C., Freitas, J. V., Lopes, N. P. \& Gaspar, L. R. (2015). Photostability evaluation of five UV-filters, trans-resveratrol and beta-carotene in sunscreens. European Journal of Pharmaceutical Sciences, 78, 79-89. https://www.sciencedirect.com/science/article/abs/pii/S0928098715003255?via\%3Dihub.

Gobbo-Neto, L.\& Lopes, N.P. (2007). Plantas medicinais: fatores de influência no conteúdo de metabólitos secundários. Química Nova, 30, 374-381. https://www.scielo.br/pdf/qn/v30n2/25.pdf.

Harrison, E. H. (2012). Mechanisms involved in the intestinal absorption of dietary vitamin A and provitamin A carotenoids. Biochemistry and biophysics acta, 70-77. https://www.ncbi.nlm.nih.gov/pubmed/21718801.

Havas, F., Krispin, S., Meléndez-Martínez, A. \& Oppen-Bezalel, L. V. (2018). Preliminary Data on the Safety of Phytoene- and Phytofluene-Rich Products for Human Use including Topical Application. Journal of Toxicology, 1-9. https://doi.org/10.1155/2018/5475784.

Islam, M., Wahid, K. \& Dinh A. (2018). Assessment of Ripening Degree of Avocado by Electrical Impedance Spectroscopy and Support Vector Machine. Hindawi, Journal of Food Quality, 2-10. https://www.hindawi.com/journals/jfq/2018/4706147/.

Kim, D. O., Lee, K. W., Lee, H. J. \& Lee, C. Y. (2002). Vitamin C equivalent antioxidant capacity (VCEAC) of phenolics phytochemicals. Journal of Agricultural Food and Chemistry, 50, 3713-3717. https://www.ncbi.nlm.nih.gov/pubmed/12059148. 
Kowalski, R. L., Schneider, V.S. \& Moretto, J., L. F. S. (2017). Produção de etanol de segunda geração a partir de caroço de abacate (Persea americana Mill.). Revista Brasileira de Energias Renováveis, 6, 665-677. https://revistas.ufpr.br/rber/article/view/49073.

Lima, J. M., Thomazini, M., Trindade, C. S. F. \& Santos, M. G. (2017). Extração de $\beta$-caroteno da macaúba. The Journal of Engineering and Exact Sciences $J C E C, 3,1-6$. https://www.researchgate.net/publication/320883081_EXTRACAO_DE_b-CAROTENO_DA_MACAUBA.

Mala, K. S., Rao, P. P., Prabhavathy, M. B.\& Satyanarayana, A. (2015). Studies on application of annatto (Bixa orellena L.) dye formulations in dairy products. Journal Food Science Technology, 52, 912-919. https://www.ncbi.nlm.nih.gov/pmc/articles/PMC4325075/pdf/13197_2013_Article_1038.pdf.

Mashmoul, M., Azlan, A., Khaza' Ai, H., Yusof, B. N. M. \& Noo, S. M. (2013). Saffron: A Natural Potent Antioxidant as a Promising Anti-Obesity Drug. Antioxidants, 2, 293-308. https://www.ncbi.nlm.nih.gov/pmc/articles/PMC4665515/pdf/antioxidants-02-00293.pdf.

Mesquita, S. S., Teixeira, C. M. L. L. \& Servulo, E. F. C. (2017). Carotenoides: Propriedades, Aplicações e Mercado. Revista Virtual de Química, 9, 672-688. http://rvq.sbq.org.br.

Moreno, E., Ortiz, B. L. \& Restrepo, L. P. (2014). Conteúdo total de fenóis e atividade antioxidante em alguns trechos da polpa de frutas tropicais. Revista Colombiana de Química, 43, 41-48. http://www.scielo.org.co/pdf/rcq/v43n3/v43n3a06.pdf.

Moura, R. L. (2019). Avaliação do comportamento de ansiedade na prole de ratas suplementadas com óleo e polpa de abacate (Persea americana mill.) durante a gestação e lactação. 55p. Monografia (Bacharelado em Nutrição) - Universidade Federal de Campina Grande, Centro de Educação e Saúde, Cueté$\mathrm{PB}, 2019$.

Müller L., Caris-Veyrat. C., Lowe, G.\& Böhm, V. (2015). Lycopene and its antioxidant role in the prevention of cardiovascular diseases. A critical review. Critical Reviews in Food Science and Nutrition, 56, 1868-1879.: https://www.researchgate.net/publication/272187744_Lycopene_and_Its_Antiob xidant_Role_in_the_Prevention_of_Cardiovascular_Diseases_-_A_Critical_Review/link/56ea7a3808ae3a5b48cd8cab/download.

Nassau, F. F. (2013). A influência dos compostos bioativos do abacate na fisiopatologia do câncer prostático e hiperplasia benigna prostática. 37p. Monografia (Bacharelado em Nutrição) - Centro Universitário de Brasília, Brasília, 2013.

Ng, M. H. \& Choo, Y.M. (2016). Improved Method for the Qualitative Analyses of Palm Oil Carotenes Using UPLC. Journal of Chromatographic Science, 54, 33-638. https://www.researchgate.net/publication/297584764_Improved_Method_for_the_Qualitative_Analyses_of_Palm_Oil_Carotenes_Using_UPLC.

Nogueira-de-Almeida, C. A., Ued, F. V., Almeida, C. C. J. N., Almeida, A. C. F., Ciampo, L. A. D., Ferraz, I. S., Silva, L. F. O., Zambom, C. R. Z. \& Oliveira, A. F. (2018). Perfil nutricional e benefícios do azeite de abacate (Persea americana): Uma revisão Integrativa. Brazilian Journal of Food Technology, 21, e2017214. https: //doi.org/10.1590/1981-6723.21417.

Oliveira, A. P., Guimarães, I. C. \& Menezes, E. G. T. (2017). Caracterização da polpa de abacate (Persea americana Mill) da região do alto Paranaíba. The Journal of Engineering and Exact Sciences - JCEC, 3, 63-69. https://www.researchgate.net/publication/320883900_CARACTERIZACAO_DA_POLPA_DE _ABACA TE_Pers ea_americana_MILL_DA_REGIAO_DO_ALTO_PARANAIBA.

Oliveira, A. P.\& Menezes, E. G. T. (2017). Extrações de óleo da polpa de abacate (Persea americana Mill) utilizando diferentes solventes. The Journal of Engineering and ExactSciences - JCEC, 3, 120-127. https://www.locus.ufv.br/bitstream/handle/123456789/20130/artigos.pdf?sequence=1\&isAllowed=y.

Oliveira, I. C. C.\& Santos, M. C. T. (2016). Os benefícios do consumo do abacate. Revista Conexão Eletrônica, 13, 1-8. revistaconexao.aems.edu.br.

Pereira et al (2018). Methodology of cientific research. UFSM https://repositorio.ufsm.br/bitstream/handle/1/15824/Lic_Computacao_Metodologia-PesquisaCientifica.pdf?sequence=1.

Re, R., Pellegrini, N., Proteggente, A., Pannala, A., Yang, M. \& Riceevans, C. (1999). Antioxidant activity applying an improved ABTS radical cation descolorization assay. Free Radical Biology and Medicine, 26, 1231-1237.

Reboul, E. (2013). Absorption of vitamin A and carotenoids by the enterocyte: focus on transport proteins. Nutrients, 5, 3563-3581. https://www.ncbi.nlm.nih.gov/pmc/articles/PMC3798921/pdf/nutrients-05-03563.pdf.

Rodrigues-Amaya, D. B., Kimura, J. \& Amaya-Farfan, J. (2008). Fontes brasileiras de carotenóides: tabela brasileira de composição de carotenóides em alimentos, Lidio Coradin e Vivian Beck Pombo, Organizadores. - Brasília: MMA/SBF, 100 p. https://www.mma.gov.br/estruturas/sbf_agrobio/_publicac ao/89_publi cacao09032009113306.pdf.

Rodriguez-Amaya, D. B. (2001). A guide to carotenoid analysis in foods. Washington: ILSI PRESS, 71p. http://beauty-review.nl/wpcontent/uploads/2014/11/A-guide-to-carotenoid-analysis-in-foods.pdf.

Rodriguez-Amaya, D. B. (2004). Avanços na pesquisa de carotenoides em alimentos: contribuições de um laboratório brasileiro. Revista Instituto Adolfo Lutz, 63, 129-38. http://www.ial.sp.gov.br/resources/insituto-adolfo-lutz/publicacoes/rial/2000/rial63_2_completa/987.pdf.

Rodriguez-Amaya, D. B. (2010). Quantitative analysis, in vitro assessment of bioavailability and antioxidant activity of food carotenoids - A review. Journal of Food Composition and Analysis, 23, 726-740. https://www.sciencedirect.com/science/article/abs/pii/S0889157510001298.

Santos-Sánchez, N. F., Salas -Coronado, R. S. A., Villanueva-Cañongo, C. \& Hernández-Carlos, B. (2019). Antioxidant Compounds and Their Antioxidant Mechanism. In: Antioxidants; Intech Open: London, UK. https://www.researchgate.net/publication/332114729_Antioxidant_Compounds_a nd_Their_Antioxidant_Mechanism.

Schiozer, A. L. \& Barata, L. E. S. (2007). Estabilidade de Corantes e Pigmentos de Origem Vegetal. Revista Fitos, 1, 6-24. http://revistafitos.far.fiocruz.br/index.php/revista-fitos/article/view/71.

Segovia, F. J., Hidalgo, G. I., Villasante, J., Ramis, X. \& Almajano, M. P. (2018). Avocado Seed: A Comparative Study of Antioxidant Content and Capacity in Protecting Oil Models from Oxidation. Molecules, 23, 1-14. https:/www.ncbi.nlm.nih.gov/pmc/articles/PMC6222478/. 
Research, Society and Development, v. 10, n. 8, e45010817500, 2021

(CC BY 4.0) | ISSN 2525-3409 | DOI: http://dx.doi.org/10.33448/rsd-v10i8.17500

Silva, A. O., Sampaio, F. A., Queiroz, I. P. C. S., Conceição, K. N.\& Silva, V. F. (2016). Antioxidant Power of carotenoids, flavonoids and vitamin e in preventing arteriosclerosis. Portuguese Reon Facema, 2, 320-324.

Souza, A. L. A. (2014). Abacate e possíveis propriedades funcionais. 2014. 25f. Trabalho de conclusão de curso (Bacharelado em Nutrição), Universidade Católica de Brasília. Brasília. https: //docplayer.com.br/67289116-Abacate-e-possiveis-propriedades-funcionais.html.

Vinha, A. F., Soares, M. O., Herdeiro, T. \& Machado, M. (2012). Chemical composition and antioxidant activity in portuguese diospyrus kaki fruit by geographical origins. The Journal of Agricultural Science, 4, 281-289. https://www.researchgate.net/publication/51995129_Chemical_composition_and_an tioxidan t_act ivity_of_portuguese_Diospyrus_kaki_fruit_by_geographical_origins.

Zakar, T., Laczko-Dobos, H., Toth, T. \& Zoltan, G. (2016). Carotenoids Assist in Cyanobacterial Photosystem II Assembly and Function. Frontiers in plant science, 7, 1-7. https://www.researchgate.net/publication/297756266_Carotenoids_Assist_in_Cyanobacterial_Photosystem_II_Assembly_and_Functio $\mathrm{n} / \mathrm{link} / 56 \mathrm{e} 5 \mathrm{db} 7408 \mathrm{ae} 65 \mathrm{dd} 4 \mathrm{cc} 0 \mathrm{~d} 6 \mathrm{fb} /$ 